\title{
DE QUE MANEIRA O AFASTAMENTO DA ÉTICA É
} LESIVO À CIÊNCIA?

\author{
Jenner Barretto Bastos Filho \\ Instituto de Física \\ Programa de Pós-Graduação em Desenvolvimento e Meio Ambiente \\ Instituto de Geografia, Desenvolvimento e Meio Ambiente \\ Universidade Federal de Alagoas \\ Maceió - AL
}

\begin{abstract}
Resumo
O nosso objetivo aqui é o de responder se é sustentável a tese que assevera a radical independência entre a excelência de um cientista de um lado e, de outro, a sua má postura Ética. A nossa resposta é a seguinte: ainda que, em casos singulares, seja concebível uma coexistência que poderia favorecer a tese da independência, essa coexistência é deletéria para o próprio e sadio desenvolvimento da ciência, enquanto instituição, pois esse desenvolvimento, se realmente for sadio, então irá requerer altos padrões éticos e cognitivos. As conseqüências dessa coexistência são desastrosas para a educação, a paz, o ambiente, a democracia e a solidariedade entre os povos.
\end{abstract}

Palavras-chave: Ética; Ciência; Afastamento entre Ética e Ciência.

\begin{abstract}
We would like to study the sustainability of the thesis asserting a radical independence between, on one side, the scientific excellence of somebody and, on the other, his (or her) bad ethical
\end{abstract}

\footnotetext{
${ }^{+}$In which way is harmful to Science the moving away of Ethics?

* Recebido: agosto de 2008.

Aceito: outubro de 2008.
} 
attitude. We argue that although the possibility of coexistence of scientific excellence with bad ethics can be conceived in singular cases, it is severely harmful for the healthy development of Science as an institution. In fact, this development requires high ethical and cognitive standards. The consequences of this coexistence for education, peace, environment, democracy and the solidarity among peoples are catastrophic.

Keywords: Ethics; Science; Science far from Ethics.

\section{Colocação do problema}

Muito freqüentemente se concebe que Ética e Ciência são campos separados e, em larga medida, independentes entre si. Para sustentar essa tese, muitos exemplos são trazidos à baila entre os quais destacamos: (i) Edward Teller (19082003) foi um físico excelente, porém de caráter ético muito duvidoso; ele recebeu o Prêmio Ig Nobel da Paz ${ }^{1}$, em 1991, por seu envolvimento no projeto de construção de armas de destruição em massa; (ii) Fritz Haber foi um químico de proa e, por conseguinte, excelente em sua atividade profissional stricto sensu; porém a sua participação no episódio dos gases venenosos, durante a primeira Guerra Mundial (1914-1918), o converteu em pessoa eticamente reprovável²; (iii) Luis Alvarez (1911-1988), Prêmio Nobel de Física de 1968, foi um cientista de grande versatilidade, tendo dominado, durante a sua carreira de físico, muitos campos de atividade de pesquisa; no entanto, ele estava no Enola Gay ${ }^{3}$, no momento em que foi lançada a bomba de Hiroxima, na manhã de 6 de agosto de 1945. Apesar de sua reconheci-

\footnotetext{
${ }^{1}$ Ver http://en.wikipedia.org/wiki/List_of_Ig_Nobel_Prize_winners\#1991. Segundo o que está disposto nesta página eletrônica, o motivo alegado desta concessão foi o de Teller ter sido o pai da bomba de Hidrogênio. Foi também um dos maiores incentivadores do programa Guerra nas Estrelas, além de ter mudado a concepção daquilo que entendemos por paz. Trata-se, evidentemente, de um prêmio que constitui uma manifestação de ironia.

2 uma análise circunstanciada em (FARIA, BASSALO, FERREIRA, 2006) principalmente no cap. 9, no qual são trazidos à baila os exemplos de Fritz Haber e de Louis Frederick Fieser.

3

Avião do qual foi lançada a bomba de Hiroxima.
} 
da excelência científica, o episódio de uma participação tão direta em um crime contra a Humanidade, não pode absolvê-lo eticamente ${ }^{45}$.

Todos os três exemplos acima e muitos outros, referidos e discutidos na literatura, são quase unânimes em reforçar uma pretensa independência que aqui pode ser expressa pela disjunção entre, de um lado, a excelência específica do cientista em sua disciplina, e, de outro, a sua postura Ética perante si, sua família, a sociedade e, mais geralmente, perante a Humanidade. Se for concebida desse modo, a Ética seria, então, encarada como uma mera externalidade à qual o cientista poderia ou não se ater; porém, os princípios éticos não teriam quaisquer influências no que concerne à excelência estrita deste enquanto cientista.

Nosso objetivo, neste trabalho, é o de questionar se uma análise mais abrangente e profunda do problema permite corroborar a tese acima e se a mera consideração aligeirada, baseada em exemplos tomados de per si, não esconderia uma realidade subjacente de um entrelaçamento muito maior entre esses dois campos tão duramente separados nessa pressuposta dicotomia.

\section{Ampliando a discussão}

A obra científica de Einstein (1879-1955) é excelente e tal afirmativa constitui amplo consenso. A vastíssima literatura sobre Einstein também exibe análises de sua vida e de sua obra segundo abordagens muito diversificadas (ver, por exemplo, MAMONE CAPRIA, 2005; MEDEIROS \& MEDEIROS, 2006; PAIS, 1995). Os dilemas éticos de Einstein, não raro, constituem matéria de amplas considerações. Mais recentemente, John Stachel do Einstein Papers Project descobriu em 1986 (ISAACSON, 2007), a existência de uma filha de Einstein com sua primeira esposa, Mileva Maric, chamada Lieserl ${ }^{6}$, nascida antes do casamento.

\footnotetext{
4 "The atomic bombs that ended World War II, Little Boy and Fat Man, were delivered to Hiroshima and Nagasaki from an airfield on Tinian, a small island in the Mariana chain, between Guam and Saipan. An American physicist, thirty-four years old in 1945, I was there at the time and flew the first of the two historic missions, the leader of a small group responsible for monitoring the energy of the explosion" (ALVAREZ, 1987; trata-se da primeira frase do primeiro capítulo deste livro).

${ }^{5}$ Para uma análise circunstanciada deste episódio, ver (BASTOS FILHO, 2008).

${ }^{6}$ "As cartas foram descobertas por John Stachel, do Einstein Papers Project, num lote de quatrocentas cartas familiares guardadas no cofre de um banco na Califórnia pela segunda mulher do filho de Einstein, Hans Albert Einstein, cuja primeira mulher fora a Zurique
} 
Como podemos constatar, essa descoberta foi feita numa época que já datava de mais de 30 anos após a morte de Einstein.

Lieserl nasceu em fevereiro de 1902 em Novi Sad, cidade da Sérvia e, talvez, tenha morrido de escarlatina em setembro de 1903.

O ocultamento programático de uma filha nascida antes do casamento em função de evitar eventuais problemas que poderiam afetar a carreira do pai, que estava em vias de ser aceito como funcionário público do escritório de patentes em Berna, é em si próprio uma questão Ética de importância.

Independentemente da gravidade do caso, quem adota a tese da dicotomia restrita entre Ética e excelência científica não verá quaisquer dificuldades em conceber a coexistência do Einstein, cientista excelente e epistemólogo refinado, com o Einstein enquanto pai, talvez descuidado e marido pouco atento à esposa. No final de sua vida, Einstein, em carta à família Besso, ao se manifestar sobre o falecimento de seu amigo de juventude Michele Ângelo Besso (1873-1955), cuja amizade foi cultivada durante toda a vida, reconhece que não foi bem sucedido enquanto marido ${ }^{7}$. É importante ressaltar que os relatos sobre o caráter do Einstein pai são, como um todo, carregados de não desprezível complexidade. Há o relato do Einstein amoroso a construir brinquedos a partir de caixas de fósforos para um entretenimento alegre e feliz com o seu filho Hans Albert (1904-1973) e também há relatos de grande distanciamento de Einstein em relação a seu filho Eduard (1910-1965), que veio a falecer em um hospital psiquiátrico de Zurique. No que diz respeito às adoções de atitudes políticas, Einstein também se revela como uma personalidade complexa. No seu período berlinense (1914-1932), o mesmo Einstein pacifista, que se recusa a assinar um manifesto que identifica a ciência alemã ao militarismo ${ }^{8}$, coexiste com o Einstein que contribui para pesquisas sobre o giros-

liberar o apartamento de Mileva Maric após a morte desta, em 1948, e levara as cartas para a Califórnia." (ISAACSON, 2007, p. 94, nota de rodapé).

${ }^{7}$ Numa carta de Einstein de março de 1955, escrita logo após a morte de seu amigo Michele Ângelo Besso e expedida à família Besso, lê-se: "O que mais admirei nele como ser humano foi o fato de ter conseguido viver muitos anos não só em paz, mas também em harmonia com uma mulher - um empreendimento em que falhei desgraçadamente por duas vezes" (ver PAIS, 1995, p. 357).

${ }^{8}$ Trata-se do Manifesto Fulda publicado nos jornais alemães no dia 4 de outubro de 1914, assinado por 93 intelectuais, entre os quais, além de Fritz Haber e Philipp Lenard, também Max Planck, Emil Fischer, Paul Ehrlich, Richard Willstätter, Wilhelm Ostwald, Walter Nernst (ver CORNWELL, 2003, p. 60-61). Era uma peça propagandística que, além de esconder os ataques contra civis na Bélgica, continha frases como "Não fosse o militarismo 
cópio e sobre asas de avião, pesquisas estas com relevante proximidade a interesses militares, fato que revela certo grau de ambigüidade. O episódio da carta escrita a Franklin Roosevelt, em 1939, por incitação de Leo Szilard, e já no seu período estadunidense (1933-1955), é elogiado por uns e severamente criticado por outros. No entanto, as posições de Einstein contra o militarismo, contra o macarthismo, e a sua defesa firme em prol da paz, mostram o valor ético de Einstein. Os episódios do manifesto Russell-Einstein , da solidariedade hipotecada a personalidades como Oppenheimer $^{10}$, Charles Chaplin, Bertrand Russell ${ }^{11}$ e David Bohm ${ }^{12}$, bem como a solidariedade prestada ao casal Rosenberg ${ }^{13}$ e a outros que viveram momentos dramáticos e, alguns deles, até trágicos, são unânimes em corroborar tanto o seu valor ético quanto as suas autonomias, intelectual e política. Isso se reforça quando trazemos à baila as críticas argutas, pertinentes e duras contra o american way of life.

Mas em relação aos aspectos duvidosos do comportamento de Einstein, notadamente o caso Lieserl, não seria mais um exemplo a corroborar, além dos três anteriormente aqui mencionados, a tese da independência entre valor ético e excelência acadêmica?

Haveremos de convir que os três exemplos anteriores - o de Teller, o de Haber e o de Alvarez - são imensamente mais graves que o exemplo sobre Lieserl.

alemão, a cultura alemã teria sido varrida da face da Terra" e "Devemos levar esta luta até o fim, como uma nação culta, uma nação que abriga o legado de Goethe, Beethoven e Kant, tão sagrada quanto o lar e a família” (Ver ISAACSON, 2007, p. 222)

Foram signatários desse importante manifesto Max Born, Percy W. Bridgman, Albert Einstein, Leopold Infeld, Frederic Juliot-Curie, Herman J. Muller, Linus Pauling, Cecil F. Powell, Joseph Rotblat, Bertrand Russell e Hideki Yukawa. Para o texto do manuscrito, em uma tradução em português, ver SOUZA BARROS, 2005.

${ }^{10}$ Ver ISAACSON, 2007, p. 539-544; PAIS, 2007, p. 276-286.

${ }^{11}$ Ver RUSSELL, 1972, p. 68-71, especialmente p. 71. Na época do tumulto no College of the New York City, em 1940 quando Russell foi acusado de ensinar coisas atentatórias à moral cristã, Einstein, com a sua habitual ironia, escreveu um texto que traduzido para o português é: "Fica repetindo-se neste Mundo tão puro e honesto: O Pároco alarma a populaça, o Gênio é executado." Para o relato de Russell sobre o episódio, ver RUSSELL, 1970, p. 305-314.

${ }^{12}$ Ver PAIS, 2007, p.141.

${ }^{13}$ Ver ISAACSON, 2007, p. 534. 
E é necessário aqui enfatizar, com todas as letras e mais uma vez, a enorme assimetria entre, por um lado, os três exemplos anteriormente referidos e, por outro, o exemplo sobre o caso Lieserl. Apesar disso, a questão Ética também aparece, sem qualquer dúvida, neste quarto exemplo. Como sabemos, a opinião pública, sinceramente ou não, não apoiou Pelé no episódio de sua filha fora do casamento, não tanto pelo fato de ter sido uma paternidade extraconjugal, mas, principalmente, pela sua relutância em reconhecer a filha. Além disso, quando sua filha morreu, vítima de câncer, Pelé sequer foi ao seu enterro. Na ocasião, foram emitidos pareceres que foram juízos de valor nada alvissareiros sobre o caso.

Retornemos ao problema da dicotomia radical acima aludida. Argumentamos que a questão deva ser analisada em um contexto mais amplo. Faz-se necessário, portanto, que nos afastemos do caso Lieserl e também de análises puramente singulares e descontextualizadas em relação aos outros três casos precedentemente abordados. E este afastamento deve ser tal que respeite a grande assimetria que existe entre, por um lado, os casos respectivamente de Teller, Haber e Alvarez, e, por outro, o caso sobre Lieserl. No que diz respeito a este último caso, seria uma atitude extremista julgar o caráter ético da obra e da vida de Einstein por eventuais deslizes cometidos em sua vida pessoal, ainda que esses sejam de alguma gravidade. Todos os seres humanos, inclusive aqueles tidos como os mais virtuosos, cometem deslizes que, evidentemente, têm origem na essencial imperfeição humana. Nos casos respectivamente de Teller, Haber e Alvarez, não podemos concebê-los, simplesmente como meros deslizes originados por uma essencial imperfeição humana, devido ao fato de serem imensamente mais graves e de conseqüências bem mais abrangentes para a Humanidade. $\mathrm{O}$ afastamento de que devemos manter em relação a esses três casos diz respeito a uma análise simplesmente singular, sem contextualizá-los como eventos sociais e históricos, conectados a uma perversa instrumentalização da ciência.

Se assim o fizermos, veremos que aquilo que, à primeira vista, parecia como dicotomia nos exemplos singulares analisados sem a devida profundidade, na verdade, se dilui e se dissolve quando refinamos a nossa análise. O processo de Institucionalização da Ciência passou, cada vez mais, a se constituir em um entrelaçamento de complexidade crescente, envolvendo interesses de ordens acadêmicas, políticas, industriais e militares. Como conseqüência, isso afetou e vem afetando de maneira drástica - e não raro de maneira deveras trágica - a própria produção da ciência e da tecnologia. Mostraremos também que tais conseqüências são tanto Éticas quanto cognitivas. Dessa maneira, os padrões éticos e cognitivos são pesadamente afetados pela prática da ciência. 


\section{O advento da Big Science e sua implicação para os padrões éticos e cognitivos da atividade científica}

Que as relações entre os cientistas, a guerra e o militarismo sempre permearam a História Social da Ciência e da Tecnologia é um dado realçado por várias correntes de estudiosos. Bem antes da Revolução Científica do século XVII europeu, Arquimedes envolvera-se na defesa de Siracusa contra as galeras romanas. Como outro exemplo, e desta feita, já no século XX, ao qual já fizemos menção, Fritz Haber liderou as pesquisas sobre gases venenosos que foram utilizados durante a primeira grande guerra mundial, de 1914-1918. Como outro exemplo, podemos ver que a politização extrema, ou ideologização, das pesquisas que pretendiam contribuir para dirimir entre o que era inato e o que era adquirido, levaram a distorções homéricas com sérias conseqüências Éticas e cognitivas, que afetaram de maneira nada desprezível o desenvolvimento da ciência biológica, em especial a genética. Caso emblemático a respeito é o de Lissenko.

Houve uma época, contudo, que um fenômeno, constituído por um complexo de confluências envolvendo a academia, a indústria e o militarismo, começava a se configurar de maneira cada vez mais sistemática. Nos países científica e tecnologicamente mais desenvolvidos, pôde-se constatar uma intensa confluência do gênero, já no final do século XIX e início do século $\mathrm{XX}^{14}{ }^{15} 16$.

No entanto, há quem arbitre que a Institucionalização, a pleno título, do complexo industrial-militar com participação ativa e legitimadora da academia, constituiu-se em um fenômeno que tem origem no mega-projeto que representou um espantoso esforço para a construção das primeiras bombas atômicas em pleno período da segunda guerra mundial. Trata-se do Projeto Manhattan do governo dos EUA, contando com alguma participação também do governo britânico.

A questão crucial é que os esforços de guerra e, em tempos chamados de paz, os esforços de conquista de mercados no contexto de uma concorrência desle-

\footnotetext{
${ }^{14}$ Ver CORNWELL, p. 56-58, 2003.

${ }^{15}$ Segundo a denúncia apresentada pelo Dr. Matthias Rath ao Tribunal Penal Internacional (ver RUESCH, 2005, p.242-248), os grupos Rockfeller nos EUA e o grupo financeiro Rothschild na Europa já eram grandes monopólios no final do século XIX e no começo do século XX. O grupo Rockfeller Standard Oil (hoje Exxon e, no Brasil, Esso) era o principal grupo farmacêutico-petroquímico dos EUA e o segundo maior grupo era a IG Farben com sede na Alemanha. A IG Farben financiou a ascensão nazista ao poder.

${ }^{16}$ Ver BARACCA, 2005.
}

Cad. Bras. Ens. Fís., v. 26, n. 1: p. 103-124, abr. 2009. 
al são incompatíveis com a livre circulação de idéias, com a discussão aberta e plural e com a suficiente abrangência com relação à própria escolha dos temas de interesse. O complexo industrial-militar e, com este, uma parte considerável da Big Science, criam juntos um aparelhamento que está sujeito aos ditames do poder e isto restringe severamente a necessária liberdade do cientista. As conseqüências Éticas em termos de uma crescente degradação dos padrões éticos, envolvendo atitudes de venalidade e de carreirismo, são por demais evidentes.

Mas não são apenas as consequiências Éticas negativas, no sentido estrito do termo, que emergem do fenômeno da Big Science como este consubstanciado pelo Projeto Manhattan. Há, de fato, consequiências cognitivas de grande relevância para que venhamos a estudar se a dicotomia referida acima se sustenta.

De fato, o advento da Big Science, tal como a que se configurou no Projeto Manhattan, constitui um extremo dirigismo de atividades, o que, necessariamente, implica em perda de autonomia e independência dos cientistas nela envolvidos. Poder-se-ia argumentar que se trata apenas de um dirigismo político e, se pensarmos particularmente no caso do projeto Manhattan, de uma severa vigilância, mas que, exceto isso, o cientista teria espaço para manifestar a sua excelência enquanto cientista sem grandes peias nem restrições, pois estava perante um desafio de monta. Assim Fermi, Alvarez, Oppenheimer, Teller e todos os demais que participaram do Projeto Manhattan estariam desafiados a desenvolver as suas autonomias e independências científicas da melhor maneira que pudessem. É interessante enfatizar que apesar desse fato ser, em larga medida, verdadeiro e que, ademais, todos esses eram espíritos de elevada competência ao nível mesmo da excelência, isto não implica, por si só, que a institucionalização de um dirigismo político do gênero não acarretasse conseqüências deletérias para a própria atividade científica no seu conjunto. Essa institucionalização, contendo esse grande defeito de origem, implicou uma degradação célere dos padrões cognitivos e éticos da atividade científica como um todo.

Em função do guarda-chuva abrangente que a expressão Big Science comporta, não seria nem justo nem correto se viéssemos a considerar que as configurações e as organizações possíveis dos empreendimentos científicos que envolvem muitos pesquisadores, financiamentos de vulto, equipamentos complexos e grandes projetos fossem, todas elas, exatamente iguais quanto às conseqüências Éticas e cognitivas para a instituição da ciência e para a sua estrutura e seu funcionamento. Por uma questão de justiça, haveremos de convir que a configuração de uma organização que acarreta uma Big Science, como a constituída pelo Projeto Manhattan, é radicalmente diferente de uma configuração de uma Big Science 
envolvendo cientistas que trabalham em Física de Altas Energias, como os que estão engajados, direta ou indiretamente, nos experimentos excitantes e cheios de promessas do LHC (Large Hadron Collider), recentemente construído em Genebra, Suíça. No caso do Projeto Manhattan, o que houve foi um empreendimento bélico, secreto, hegemônico e muito vigiado. No caso do LHC, muito pelo contrário, cientistas de vários países entram em consórcio em busca de soluções, ainda que parciais, para problemas complexos, os quais não poderiam ser investigados sem uma colaboração do gênero. Enquanto no primeiro caso, o caráter secreto impede a circulação de idéias, no segundo caso há o compartilhamento dos resultados.

Outro ponto importante é que a conquista cognitiva que uma eventual ou não detecção do bóson de Higgs possa propiciar se insere em um contexto de paz e compartilhamento de resultados, o que promove a dignidade humana pela capacidade de sua inteligência. No caso do Projeto Manhattan, ainda que admitamos a conquista cognitiva alcançada em nível da realidade estudada pela Física Nuclear e pela então nascente Tecnologia Nuclear, a utilização dos artefatos correspondentes que foram lançados em cidades, sem dúvida, representou uma grande degradação da dignidade humana.

\section{A tese de Sen de que o afastamento entre a Ética e a economia foi lesivo ao desenvolvimento da própria ciência econômica}

A concepção quase sempre aceita é aquela segundo a qual Ética e economia são campos separados. Constatamos que a dicotomia entre Ética e economia também está bastante disseminada entre os economistas. No entanto, o economista Amartya Sen, vencedor do Prêmio Nobel de Economia de 1998, contesta essa concepção (SEN, 1999). Os defensores da tese que Amartya Sen critica severamente, quase sempre invocam o Pai da moderna ciência econômica - Adam Smith - como aquele que seria o responsável por tal separação entre a economia e a Ética.

Amartya Sen argumenta que essa tese da separação é equivocada e, ademais, se constitui numa leitura apressada e que não faz jus à grandeza do pensamento de Smith. Considera Sen que Smith, que era Professor de Filosofia Moral da Universidade de Glasgow, Escócia, seria esquizofrênico se realmente pensasse que a economia não deva ser regida por questões Éticas, inclusive envolvendo bonomia. 
Uma das fontes desse equívoco seria a célebre passagem na qual Smith argumenta que não é da generosidade do cervejeiro, do padeiro e do açougueiro que esperamos obter o nosso jantar, mas sim do auto-interesse dos mesmos ${ }^{17}$. Sen assevera, contudo, que uma leitura atenta e perspicaz da obra smithiana constatará que o pai da moderna ciência econômica também ressalta a necessidade de políticas públicas que envolvam generosidade e bonomia em nome do bom desenvolvimento da própria economia e de um desenvolvimento mais abrangente enquanto exercício das liberdades (SEN, 2000).

Podemos, ainda, aduzir a combinação virtuosa entre competição leal e cooperação sinérgica e também a necessidade de combate à pleonexia enquanto competição predatória, avara, desleal e lesiva ao desenvolvimento genuíno (Ver MONTEIRO et. al., 2006; AYRES et al., 2009).

O ponto que nos interessa destacar aqui é que essa tese de Sen, que assevera que a separação entre Ética e economia foi lesiva para a própria ciência econômica, encontra defensores. Fato menos evidente, contudo, diz respeito aos eventuais defensores da tese segundo a qual um análogo afastamento entre Ética e Física teria sido lesivo ao desenvolvimento da própria Física. Freqüentemente, ouvimos exatamente o contrário, ou seja, que apesar das grandes violações Éticas acarretadas pelo estado de guerra - que envolveram campos de concentração e trabalho escravo - e pelas competições desleais por mercado, emergiram grandes conquistas cognitivas como o radar, a bomba, os foguetes, entre outros.

Apesar de tudo isso, se olharmos no conjunto, veremos que tanto os esforços exorbitantes em prol de interesses bélicos quanto daqueles esforços exagerados e exclusivistas em interesses de mercado distorcem o livre desenvolvimento e a liberdade de escolha dos cientistas, fazendo-os atrelados a interesses mais poderosos, o que, sem dúvida, favorece tanto o carreirismo e a competição desleal quanto favorece a própria prática da venalidade. Aquilo que até pode ser visto pelos incautos como meras e espontâneas manifestações de "moda" são, na realidade, manifestações de dirigismo e não é à toa que somente os poderosos ditam o que seja a moda a seguir.

\footnotetext{
17 "It is not from the benevolence of the butcher, the brewer, or the baker that we expect our dinner, but from, their regard to their own interest. We address ourselves, not to their humanity but to their self-love, and never talk to them of our own necessities but of their advantages." (SMITH, 1978, p.7)
} 


\section{A questão da degradação dos padrões éticos e cognitivos}

Embora se possa conceber legitimamente que a excelência de um cientista, enquanto tal, não está necessariamente atrelada à sua conduta Ética, e que a combinação, numa única pessoa, de uma faceta que constitua um cientista excelente com a faceta de um homem ou de uma mulher que moralmente seja um facínora, possa se constituir numa realidade concreta, ainda assim, isso não implica que a instituição da ciência seja beneficiada por tal combinação. Com muito maior razão, isso também não implica que as sociedades planetárias sejam minimamente beneficiadas.

Que um facínora que seja em excelente cientista também seja, com grande probabilidade, alguém deletério para as sociedades planetárias, não há qualquer dúvida. Menos evidente, contudo, é o fato de tal postura deletéria também contribuir negativamente para alterar os próprios padrões cognitivos de uma ciência sã ${ }^{18}$.

Grande número de autores tem enfatizado que a dicotomia fato/valor, tal como é asseverada por positivistas que proclamam uma pressuposta neutralidade axiológica no campo das ciências, não se sustenta, em vista da própria atividade científica necessariamente requerer atitudes valorativas. BUNGE (1972), por exemplo, argumenta que a atividade científica é uma escola de moral que exige honestidade intelectual, independência de juizo, coragem intelectual, amor pela liberdade intelectual e sentido de justiça. Bunge assevera que "nenhuma dessas cinco virtudes podem ser exercitadas cabalmente quando a investigação se faz em benefício de forças destrutivas, privilegiadas ou subjugadoras." (BUNGE, 1972, p. 42).

Em outras palavras, como seria possível conciliar a independência de julgamento de alguém, por exemplo, com a prática da venalidade que significa trabalhar para interesses que são impostos, o que necessariamente requer a não exibição, e não raro o próprio mascaramento, de eventuais resultados que não convêm a quem financia?

\footnotetext{
${ }^{18}$ Concebemos por ciência sãa, aquela cujos praticantes se atenham a padrões éticos e cognitivos elevados. Podemos considerar que os praticantes de uma ciência sã devem observar e cumprir as cinco virtudes apontadas por Bunge: honestidade intelectual, independência de juizo, coragem intelectual, amor pela liberdade intelectual e sentido de justiça.
} 
Muitas pesquisas constituem esforços sérios para investigar e denunciar situações do gênero que requerem especial atenção (ver, por exemplo, MAMONE CAPRIA, 2003; 2006) ${ }^{19}$.

Nesse momento, é importante aludir ao fato de que as conseqüências Éticas se correlacionam bem mais perto do que se imagina com as conseqüências cognitivas daí advindas.

É interessante mencionar que no campo da filosofia da ciência houve um debate entre Kuhn (ver KUHN, 1979) e Popper (ver POPPER, 1979) sobre as características da ciência normal. Kuhn descrevendo o seu funcionamento e Popper criticando os cientistas normais descritos por Kuhn como pessoas malensinadas e acríticas, as quais somente saberiam se ater a um paradigma e, deste modo, somente saberiam trabalhar rigorosamente dentro do referencial constituído pelo paradigma que caracteriza o empreendimento normal (para uma análise circunstanciada, ver BASTOS FILHO, 2001; 2003; 2006 e para a conexão com a crítica freireana à educação bancária, ver BASSALO, 2003). Bem entendido, a ciência normal não é necessariamente a ciência que emerge da Big Science, mas há certamente uma grande correlação entre elas. Em ambas, há camisas de força. $\mathrm{Na}$ primeira, há a camisa de força da disciplina paradigmática que é intolerante com qualquer violação ao referencial adotado; na segunda, a camisa de força é profundamente política, pois o dirigismo é tal que atende, em primeiríssima instância, aos interesses do complexo que envolve os acadêmicos com os interesses industriais e militares ou, no melhor dos casos, com gigantescos interesses de mercado. Em ambas, a autonomia dos cientistas se vê seriamente reduzida. No caso da ciência normal, a perda de autonomia é muito mais intelectual. No caso da Big Science, ainda que em muitos casos a autonomia intelectual no sentido estrito seja preservada, a perda de autonomia política é evidente.

E novamente aqui, tal como no caso da necessidade de distinguir entre os diversos tipos de Big Sciences - em função do quadro abrangente que este termo abriga - haveremos de concordar com a necessidade de trazer à baila a crítica severa de Popper à dicotomia estrita proposta por Kuhn entre ciência normal e ciência extraordinária. Popper, apesar de ter concordado que o fenômeno da ciência normal descrita por Kuhn existe e que essa modalidade de fazer ciência teria que ser combatida pelos intelectuais dignos deste nome, argumentou também em prol da imperiosa necessidade de se conceber uma gradação entre o normal e o extraordinário. O exemplo escolhido por Popper foi o de Boltzmann o qual, se-

\footnotetext{
${ }^{19}$ Ver a página eletrônica $<$ www.dipmat.unipg.it/ mamone/sci-dem $>$.
} 
gundo Popper, não estava engajado propriamente em quebras de paradigmas, pois em amplo senso era um maxwelliano e um continuador de Maxwell, mas que, apesar disso, foi um físico tão distante de ser considerado como um cientista normal quanto um cientista pode ser. Como um argumento adicional, podemos aduzir que não é o fato de alguns resultados poderem ser concebidos no quadro teórico que constitui um paradigma aceito que faria com que esses resultados não pudessem ser considerados, sob algum aspecto, como extraordinários. Por exemplo, uma eventual deteç̧ão do bóson de Higgs no LHC não deixará de ser um resultado extraordinário em que pese ser esperado no contexto do presente quadro teórico. Deste modo, além dos cortes epistemológicos à la Bachelard, ou, alternativamente, das realizações extraordinárias em época de revolução à la Kuhn, haveremos de convir que, em certo sentido, há a necessidade de se considerar a gradação reivindicada por Popper e que Lakatos chamou de revolução permanente. Em suma, o empreendimento científico é bem mais complexo do que podem dar conta quaisquer esquemas e sistematizações teóricas a respeito dele (ver BASTOS FILHO, 2000).

A propósito, retomemos a discussão sobre como podemos conceber uma ciência sã.

Uma ciência sã, tal como uma educação de qualidade, estimula tanto a autonomia intelectual quanto a autonomia política dos seus praticantes, não no isolamento, mas sim em sinergia virtuosa uns com os outros, em combinação com a competição saudável e leal. No contexto da prática de uma ciência sã, o respeito pelas potencialidades dos indivíduos é essencial. Evidentemente, os praticantes de uma ciência sã não são todos gênios (na verdade, pouquíssimos são), o que justifica o fato desses praticantes se engajarem em trabalhos de diferentes níveis de importância segundo uma gradação. No entanto, todos eles têm a obrigação de se aterem a altos padrões éticos e cognitivos. Isso pode ser considerado uma idealização da realidade frente às vicissitudes internas e externas que podem estimular a violação desta prática. No entanto, ela se coaduna com a observância das cinco virtudes apontadas por Bunge que são: honestidade intelectual, independência de juizo, coragem intelectual, amor pela liberdade intelectual e sentido de justiça. Ela se coaduna também com as conclusões em Bastos Filho, 2001 (ver também as referências do capítulo correspondente).

Efetivamente, as conseqüências que implicam uma crescente degradação dos padrões cognitivos daquilo que deveria ser uma ciência sã tornam-se evidentes, pois isso restringe severamente a capacidade de circulação de idéias e dá vazão à falta de transparência no que diz respeito à atividade científica. Uma lógica per- 
meada por razões instrumentais passa a dominar o cenário, em detrimento de uma lógica que visa os mais nobres interesses públicos, inclusive aqueles que se referem ao conhecimento, o que, por sua vez, também implica uma degradação da própria prática democrática.

Desse modo, o próprio excesso de especialização - e aqui não se trata da profundidade que um dado tema específico solicita e exige, e sim da polarização excessiva numa estreitíssima faixa de interesse, acompanhada de solene desprezo por todo o resto - leva a distorções homéricas e que, mais uma vez, são distorções tanto Éticas quanto cognitivas. O filósofo espanhol José Ortega y Gasset ${ }^{20}$ adverte que, em 1890, a geração de cientistas que passa a assumir a liderança intelectual na Europa é sem similar em toda a história. É uma época em que tem início uma singularíssima instrumentalização da ciência.

Pensadores de lavras intelectuais distintas como Kant, Pascal, Einstein, Popper, Ortega, Bunge, Paulo Freire, Celso Furtado, Gandhi, Sen, entre vários outros, convergem muito enfaticamente na conexão entre os aspectos éticos e cognitivos aqui abordados. Evidentemente, não acompanhamos nenhum desses pensadores em todos os pontos de seus pensamentos, mas podemos afirmar com ênfase que, quanto à aproximação entre a Ética e a cognição por esforço autônomo, eles formam, em que pese as suas diversidades intelectuais, um núcleo bastante compatível. Evidentemente, este núcleo de compatibilidade é um dos apoios teóricos de nossa reflexão. Acrescentamos análises e articulamos conexões de nossa própria responsabilidade, as quais sustentamos em vista da nossa própria concepção de mundo.

\footnotetext{
${ }^{20}$ Cuando en 1890 una tercera generación toma el mando intelectual de Europa, nos encontramos con un tipo de científico sin ejemplo en la historia. Es un hombre que, de todo lo que hay que saber para ser un personaje discreto, conoce sólo una ciencia determinada, y aun de esa ciencia sólo conoce bien la pequeña porción en que él es activo investigador. Llega a proclamar como una virtud el no enterarse de cuanto quede fuera del angosto paisaje que especialmente cultiva, y llama dilettantismo a la curiosidad por el conjunto del saber. El caso es que, recluido en la estrechez de su campo visual, consigue, en efecto, descubrir nuevos hechos y hacer avanzar su ciencia, que él apenas conoce, y con ella la enciclopedia del pensamiento, que concienzudamente desconoce. ¿Cómo ha sido y es posible cosa semejante? Porque conviene recalcar la extravagancia de este hecho innegable: la ciencia experimental ha progresado en buena parte merced al trabajo de hombres fabulosamente mediocres, y aun menos que mediocres. (ORTEGA Y GASSET, Edição eletrônica 2004 da Edição publicada em 1937). Disponível em:

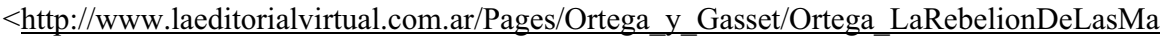
sas01.htm\#ind14>
} 
Vejamos, então, como tais apoios sustentam as nossas próprias análises ao longo do presente trabalho e comecemos por Kant.

As nossas conexões estão de acordo com Kant ${ }^{21}$, quando este argumentou que se o valor de algo não pode ter alguma equivalência (em dinheiro, por exemplo), então ele tem dignidade, o que evidentemente reprova qualquer troca, e ainda com mais razão, toda a venalidade, principalmente quando a dignidade humana estiver envolvida. Conectada com essa postura de uma Ética profunda e rigorosa está o compromisso iluminista das autonomias, respectivamente, intelectual e política, representada pelo Sapere Aude kantiano ${ }^{22}$ e, talvez ainda com maior razão, na passagem na qual Kant argumenta que o juízo autônomo de alguém não pode ser dispensado, até mesmo no caso no qual o próprio Deus apareça e se apresente a essa pessoa ${ }^{23}$. Ainda assim, argumenta Kant, essa pessoa terá necessariamente de julgar pelos seus próprios critérios e pelo seu próprio discernimento se aceita ou não esse Deus que se apresenta. Trata-se de uma das mais eloqüentes passagens de conexão entre os aspectos éticos e cognitivos de uma escolha que exige a autonomia do pensamento. Isso lembra Dostoéivski, na célebre passagem de sua obra $O s$ Irmãos Karamasov, quando o dilema moral implicado pela questão segundo a qual se Deus não existir, então tudo será permitido é trazido à baila. Se isso for verdadeiro, então leva a uma situação segundo a qual os ateus poderiam dispensar princípios éticos, pelo fato de não temerem a punição de Deus. Mas, por outro lado, se os crentes se comportam por medo e praticam o bem apenas por temor de que alguma punição recaia sobre eles, então isso não se justifica moralmente. Novamente, podemos invocar Kant quando este argumentou que uma ação somente tem o seu autêntico valor moral quando é praticada por dever e não por qualquer interesse que seja ${ }^{24}$. Em outras palavras, uma Ética por temor e também por interesses

\footnotetext{
${ }^{21}$ "No reino dos fins tudo tem ou um preço ou uma dignidade. Quando uma coisa tem um preço, pode-se pôr em vez dela qualquer outra como equivalente; mas quando uma coisa está acima de todo preço e, portanto, não permite equivalente, então tem ela dignidade" (KANT, 1960, p. 76).

${ }^{22}$ Ver POPPER, 1982, p. 204-205.

${ }^{23}$ Ver POPPER, 1982, p. 209.

24 "Admitindo pois que o ânimo desse filantropo estivesse velado pelo desgosto pessoal que apaga toda a compaixão pela sorte alheia, e que ele continuasse a ter a possibilidade de fazer bem aos desgraçados, mas que a desgraça alheia o não tocava porque estava bastante ocupado com a sua própria; se agora, que nenhuma inclinação o estimula já, ele se arrancasse a
} 
egoístas, não é uma Ética autêntica e, assim, tanto crentes como ateus podem realizar ações moralmente justificáveis ao elegerem o dever e não quaisquer interesses e temores, individuais ou não, como balizadores de suas ações.

Pascal também ressaltou o que segundo ele é a mais alta dignidade do ser humano: o seu pensamento. Desse modo, quaisquer restrições graves ao exercício do pensamento seriam também sérios atentados à dignidade humana. Poderíamos ainda citar, ao contextualizarmos para os nossos dias, as restrições das camisas-deforça de uma intolerante ciência normal e de uma Big Science dirigida muito mais para o mercado e para a obtenção de grandes lucros do que propriamente em prol da saúde pública ${ }^{25}$. Em suma, isso seria - a um só tempo - tanto um atentado contra o pensamento humano (enquanto apanágio da dignidade humana), quanto um atentado ao princípio da vida enquanto valor intrínseco.

Nessa conexão de aspectos éticos e cognitivos, fazemos agora menção a Einstein. Ele criticou severamente a tese, tão na moda nos anos 30, da dissolução da realidade que, segundo o seu parecer, constituía uma espécie de lavagem cerebral que os teóricos dos quanta propugnavam. Numa famosa carta escrita para $o$ seu amigo de juventude Maurice Solovine ${ }^{26}$, Einstein se insurgiu, criticando severamente aqueles que aboliram por decreto a necessidade de conceber a existência de uma realidade objetiva. $\mathrm{O}$ fato de se contrapor a uma moda avassaladora - por autonomia do pensamento - revela uma formidável conexão entre os valores morais de alguém que tem a coragem de se opor, por dever, a algo que fere a sua consciência e também por razões intelectuais. Einstein chama de cavalos (indivíduos que não são afeitos à reflexão) àqueles que aderem à moda.

Em relação aos aspectos em que nos utilizamos da confluência de pontos importantes dos pensamentos de Bunge, Ortega e Amartya Sen, somos da opinião

esta mortal insensibilidade e praticasse a ação sem qualquer inclinação, simplesmente por dever, só então é que ela teria o seu autêntico valor moral." (KANT, 1960, p. 22-23; as ênfases em itálicos foram acrescentadas por nós).

A fim de não pecarmos por maniqueísmo haveremos de fazer também um contraponto aqui. Certamente há fármacos que curam, mas há fármacos cuja eficácia duvidosa pode inclusive gerar doenças. O poder das indústrias farmacêuticas e a sua enorme influência sobre a academia certamente acarretam sérios problemas. A necessidade de que as primeiras têm a fim de que a academia cumpra uma função legitimadora dos interesses dessas indústrias leva a distorções que necessitam tanto do controle eficiente do Estado quanto do controle da sociedade civil através de suas organizações.

${ }^{26}$ Ver EINSTEIN, 1993, p. 85. Trata-se da carta escrita por Einstein a Solovine, no dia 10 de abril de 1938. 
de que já dedicamos espaço suficiente neste trabalho e, assim, achamos que as conexões aludidas se apresentam com bastante clareza.

Centremos a nossa atenção nos aspectos escolhidos dos pensamentos de Paulo Freire, Celso Furtado e Mahatma Gandhi. Na sua Pedagogia da Autonomia, Freire (ver FREIRE, 1999) insiste tanto na importância de uma educação crítica quanto na adoção de posturas Éticas e respeitosas para com os sujeitos da educação, enquanto elementos imprescindíveis para que venhamos a nos contrapor a uma educação bancária. A educação que Paulo Freire critica severamente e chama de educação bancária tem uma contrapartida clara com a concepção que adota de que os sujeitos devem se submeter a uma educação indutiva e repetitiva, como se esses sujeitos fossem, como diria Popper, meros baldes mentais. Nesse sentido, Celso Furtado (ver FURTADO, 2000) nos fornece um depoimento primoroso quando relata a sua necessária contraposição à concepção de Eugenio Gudim que, em finais dos anos 40 e em começos dos anos 50 do século XX, ainda propugnava que o Brasil deveria ser uma economia meramente exportadora de matéria prima agrícola. Furtado enfatiza a necessidade dos economistas latino-americanos assumirem uma postura tanto Ética quanto intelectualmente autônoma no que diz respeito ao conceito de desenvolvimento. Mahatma Gandhi também asseverou, em primorosa reflexão, que devemos estar abertos às influências das culturas, mas jamais poderemos sustentar Ética e autonomamente a dispensa de nossa própria cultura ${ }^{27}$.

Com relação ao pensamento de Popper, alguns elementos são admiráveis como: (i) a sua crítica ao positivismo; (ii) a sua crítica contundente à apologia da incompreensibilidade, tal como ele se manifestou no prefácio escrito a um importante livro de Selleri (ver SELLERI, 1986); (iii) a sua crítica à indução e à concepção de conhecimento que encara as mentes como baldes vazios; (iv) a sua admiração pelo iluminismo kantiano consubstanciada nas autonomias, intelectual e política dos indivíduos, com o grito do Sapere Aude; (v) a sua crítica aos perigos do fenômeno da ciência normal, tal como aquela descrita por Kuhn.

No entanto, há pontos que consideramos deploráveis no pensamento de Popper. O seu pensamento teria muito maior credibilidade se criticasse severamente a ideologia e as ações deletérias do imperialismo como lesivas à liberdade, ao ambiente, e aos mais legítimos interesses dos povos. Infelizmente, em uma importante instância, Popper se trai ao defender, numa entrevista à revista alemã Der Spiegel, a guerra preventiva, ao argumentar que os povos do terceiro mundo deve-

\footnotetext{
${ }^{27}$ Ver GANDHI, apud JAVIER PEREZ de CUELLAR, 1997, p. 98.
} 
riam ser tutelados, pois não alcançaram a maioridade; esses povos são, segundo Popper, como crianças deixadas ao léu em um jardim de infância ${ }^{28}$. Como, então, conciliar a tutela colonial e imperialista com a autonomia à la Sapere Aude? Muito mais coerente é a postura de Gandhi, que concilia a abertura diante das influências culturais e o exercício da imprescindível autonomia.

Aqui encerramos os nossos argumentos desta reflexão.

\section{Conclusões}

Chegamos, enfim, ao fechamento do presente trabalho. O nosso objetivo neste trabalho foi o de analisar se a tese que implica a restrita dicotomia entre, de um lado, a excelência científica de alguém e, de outro, os seus princípios éticos, constitui-se em algo sustentável.

A nossa resposta para a pergunta que constitui objetivo precípuo do presente trabalho será assim resumida:

(A) embora possamos conceber alguém que tenha desempenho científico excelente e, ao mesmo tempo, proceda segundo princípios éticos deletérios, é também forçoso reconhecer que a instituição da ciência sã se vê, em seu conjunto, enormemente prejudicada em função das pesadas conseqüências sociais daí advindas;

(B) há um prejuízo na comunidade científica como um todo, refletida na perda severa da autonomia intelectual de seus membros e, também, há uma severa perda da autonomia política das pessoas envolvidas no empreendimento científico que se vê sujeito a um aparelhamento e a uma grande probabilidade de se submeter a interesses escusos;

(C) tudo parece corroborar que, no mesmo sentido em que Amartya Sen argumentou que o afastamento da economia da Ética foi lesivo para a própria ciência econômica, assim o é igualmente o afastamento da Física em relação à Ética;

(D) Este afastamento é lesivo à educação, pois ao invés de promover a elevação de espírito, promove-se, em nome do progresso da ciência e da tecnologia, uma razão instrumental;

(E) esta razão instrumental é nociva à solidariedade entre os povos pois, neste contexto, Ética e ambiente são tratados como meras externalidades;

\footnotetext{
${ }^{28}$ Ver POPPER, 2001, p. 502-525 [Trata-se do capítulo 14 de um livro onde estão disponíveis os respectivos textos em alemão e em italiano desta entrevista concedida à revista $\mathrm{Der}$ Spiegel].
} 
(F) esta razão instrumental é lesiva à genuína democracia pois, assim, o grande poder é concentrado ou nas mãos das grandes corporações e Estados hegemônicos, ou nas mãos de ditadores de todas as lavras, senão nas mãos de ambos;

(G) a dicotomia restrita deve ser combatida.

\section{Agradecimentos}

Agradecemos aos dois árbitros pelos pertinentes comentários críticos que nos ajudaram sobremaneira a melhorar o trabalho. Agradecemos também ao nosso amigo o Prof. Marco Mamone Capria, do Instituto de Matemática da Universidade de Perugia, Itália, pela citação de Alvarez.

\section{Referências}

ALVAREZ, L. W. Adventures of a physicist. New York: Basic Books, 1987.

AYRES, F. G. S.; BASTOS FILHO, J. B. O exercício das liberdades, o combate à pleonexia, e a educação ambiental. Aceito para publicação em Gaia Scientia , 2009.

Estará disponível em: www.prodema.ufpb.br/revistagaia e em http://periodicos.ufpb.br/ojs2/índex.php/gaia

BARACCA, A. Mechanistic Science, Thermodynamics, and industry at the end of the nineteenth century. In: MAMONE CAPRIA, M. (Org.) Physics before and after Einstein. Amsterdam, Berlin, Oxford, Tokyo, Washington: IOS Press, 2005. p. 49-70.

BASSALO, J. M. F. Ensino: "Bancário" ou Holístico? Ciência e Sociedade, CBPF-CS-002/03. Disponível em:

$<$ http://www.bassalo.com.br/mm_magensino.asp $>$ Acesso em: mai. 2003.

BASTOS FILHO, J. B. Sobre os paradigmas de Kuhn, o problema da incomensurabilidade e o confronto com Popper. Acta Scientiarum, v. 22, n. 5, p. 1297-1309, 2000 .

$<\underline{\text { http://www.periodicos.uem.br/ojs/index.php/ActaSciTechnol/article/view/3064/2 }}$ $\underline{215}>$ 
A ciência normal e a educação são tendências opostas? In: BURSZTYN, M. (Org.). Ciência, Ética e Sustentabilidade. São Paulo: Ed. Cortez; Brasília: Unesco, CDS-UnB. 2001. p.61-93. Disponível em:

$<$ http://unesdoc.unesco.org/images/0012/001274/127492por.pdf $>$

Il Giudizio dei "pari” e dei “dispari”. In: MAMONE CA-

PRIA, M (Org.). Scienza e Democrazia. Nápoles: Liguori, 2003. p. 75-92.

Razionalismo, Democrazia e Filosofia della Scienza. In:

MAMONE CAPRIA, M. (Org.). Scienze, Poteri e Democrazia. Roma: Editori Riuniti, 2006. p. 89-116.

Science, Ethics and Environment. Trabalho escrito para o congresso Amazonian Symposium on Physics, em homenagem ao Professor José Maria Filardo Bassalo, realizado em Belém, Pará, em setembro de 2008. Para ser publicado in: Trends in Physics - Festschirift in Homage to Prof. José Maria Filardo Bassalo, Editora Livraria da Física, São Paulo (no prelo).

BUNGE, M. Etica y Ciencia. Buenos Aires: Siglo Veinte, 1972.

CORNWELL, J. Os cientistas de Hitler (ciência, guerra e pacto com o demônio). Rio de Janeiro: Imago, 2003.

EINSTEIN, A. Letters to Solovine (1906-1955). New York: Citadel Press, 1993.

FARIAS, R. F.; BASSALO, J. M. F.; FERREIRA, J. E. Ética e atividade científica. Campinas: Editora Átomo; Belém: Editora da Universidade Federal do Pará, 2006.

FREIRE, P. Pedagogia da Autonomia: saberes necessários à prática educativa. São Paulo: Paz e Terra, 1999.

FURTADO, C. O capitalismo global. 4. ed. São Paulo: Paz e Terra, 2000.

ISAACSON, W. Einstein sua vida, seu universo. São Paulo: Companhia das Letras, 2007.

KANT, I. Fundamentação da metafísica dos costumes. Coimbra: Biblioteca Filosófica Atlântida, 1960. 
KUHN, T. S. Lógica da Descoberta ou Psicologia da Pesquisa? In: LAKATOS, I.; MUSGRAVE, A. (Orgs.). A crítica e o desenvolvimento do conhecimento. São Paulo: Cultrix; Editora da Universidade de São Paulo, 1979, p. 5-31.

MAMONE CAPRIA, M. Scienza e Democrazia. Nápoles: Liguori Editore, 2003.

MAMONE CAPRIA, M. Physics before and after Einstein. Amsterdam, Berlin, Oxford, Tokyo, Washington: IOS Press, 2005.

MAMONE CAPRIA, M. Scienze, Poteri e Democrazia. Roma: Editori Riuniti, 2006.

MEDEIROS, A.; MEDEIROS, C. Einstein e a Educação. São Paulo: Editora Livraria da Física, 2006.

MONTEIRO, J. A. M.; AYRES, F. G. S.; BARROS, J. G.; SILVA, R. M. S. R.; TONHOLO, J.; BASTOS FILHO, J. B. Pleonexia enquanto obstáculo ao desenvolvimento. In: LAGES, V.; TONHOLO, J. (Orgs.). Desafios de competitividade em arranjos produtivos locais. Brasília: ANPROTEC, 2006. p. 41-72.

ORTEGA; GASSET, J. La Rebelión de las Masas. Disponível em: $<$ http://www.laeditorialvirtual.com.ar/Pages/Ortega_y_Gasset/Ortega_LaRebelion DeLasMasas01.htm\#ind14>

PAIS, A.. Sutil é o Senhor... A Ciência e a vida de Einstein. Rio de Janeiro: Editora Nova Fronteira, 1995.

Oppenheimer. Dalla Bomba Atomica Alla Guerra Fredda: La Tragedia di uno Scienziato. Milão: Mondadori, 2007.

PEREZ DE CUELLAR, J. Nossa diversidade criadora: relatório da Comissão Mundial de Cultura e Desenvolvimento. UNESCO, Campinas: Papirus, 1997.

POPPER, K. R. A Ciência Normal e seus Perigos. In: LAKATOS, I.; MUSGRAVE, A. (Orgs.). A crítica e o desenvolvimento do conhecimento. São Paulo: Cultrix; 1979. p. 63-71.

POPPER, K. R. Conjecturas e refutações. Brasília: Editora da Universidade de Brasília, 1982.

POPPER, K. R. Tutta la Vita è Risolvere Problemi. Milão: Bompiani, 2001. 
RUESCH, H. La medicina smascherata (L'antivivisezionismo come esperienza política). Ed. por Marco Mamone Capria. Roma: Editori Riuniti, 2005.

RUSSELL, B. Autobiografia [1914-1944]. Rio de Janeiro: Civilização Brasileira, 1970. v. II.

1972. v. III.

Autobiografia [1944-1967]. Rio de Janeiro: Civilização Brasileira,

SELlERI, F. Le Grand Débat de la Théorie Quantique. Flammarion: Paris, 1986.

SEN, A. Sobre Ética e Economia. São Paulo: Companhia das Letras, 1999.

SEN, A. Desenvolvimento como Liberdade. São Paulo: Companhia das Letras, 2000.

SMITH, A. An inquiry into the nature and cause of the wealth of nations. In: Great Books of Western World, Encyclopaedia Britannica, Inc. 1978. [Publicado originalmente em 1776]. v. 39.

SOUZA BARROS, F. O manifesto Russell-Einstein e as Conferências de Pugwash. Física na Escola, v. 6, n. 1, p. 15-22, 2005. Disponível em:

$<\underline{\text { http://www.sbfisica.org.br/fne/ }>}$ 